\section{Dr. Kaufman and Dr. Spitzer reply}

\section{To the Editor:}

The editorial that was paired with Silva's article on pregnancy outcomes in juvenile $\operatorname{SLE}^{1,2}$ was meant to generate discussion about adolescent issues, and Drs. Bidwell, Bolt, and McDonagh have continued the conversation in a well documented response. Raising awareness about adolescent sexuality is just a first step. As the writers point out, it is essential that rheumatologists and all pediatric practitioners continue to polish their skills in interacting with adolescents in a developmentally appropriate manner. This is important not only in the area of sexuality but also in discussing adherence, pain, vocational issues, and transition to adult care.

While rheumatologists need not be experts in contraception, sexual behavior, or sexually transmitted infections, they must be able to relate to their patients and probe relevant health issues in such a way that young people will disclose the need for more information or intervention about these topics. There are growing numbers of clinicians who are experts in these and other adolescent issues and who are keenly interested and available to manage medically challenging adolescents with contraceptive and sexual health needs, but these individuals still rely on their colleagues to have the skills to identify and refer the appropriate patients.

At our institution, for example, we have a Complicated Contraception Clinic that is jointly run by Adolescent Medicine and Paediatric and Adolescent Gynecology. An interprofessional team is able to offer evidence-based care to adolescents with chronic conditions who are seeking care around issues of contraceptive use and sexual health. If other adolescent issues emerge at these appointments, these youth can be followed in our Adolescent Medicine Clinic.

One point not made in the editorial or the response is that it is not unusual for adolescents with rheumatologic (and other medical) diagnoses to feel anxious about their disease and its effects on their sexuality. Having materials available that can address these anxieties can be helpful. Some suggested resources are: Living and Loving: Information About Sexuality and Intimacy ${ }^{3}$; Sexuality and Lupus ${ }^{4}$; Find Creative Ways to Enjoy Sex and Intimacy Despite Arthritis Pain ${ }^{5}$; and Easy For You To Say: Q\&As for Teens Living With Chronic Illness or Disability ${ }^{6}$. All are readily available on the Internet, at libraries, or from the Arthritis Foundation.

MIRIAM KAUFMAN, BSN, MD, FRCPC, Division of Adolescent Medicine; RACHEL F. SPITZER, BSc, MD, MPH, FRCSC, Section of Pediatric and Adolescent Gynecology, Hospital for Sick Children, 555 University Avenue, Toronto, Ontario M5G 1X8, Canada. Address reprint requests to Dr. Kaufman; E-mail: miriam.kaufman@ sickkids.ca

\section{REFERENCES}

1. Silva CAA, Hilario MO, Febronio MV, et al. Pregnancy outcome in juvenile systemic lupus erythematosus: a Brazilian multicenter cohort study. J Rheumatol 2008;35:1414-8.

2. Kaufman M. Pregnant adolescents and youth with systemic lupus erythematosus: can new data inform our approach to young women with SLE? J Rheumatol 2008;35:1240-1.

3. Living and loving: Information about sexuality and intimacy. Atlanta: The Arthritis Foundation; 2005.

4. Sexuality and lupus. Lupus UK. Internet. Accessed Dec 18, 2008. Available from: http://www.uklupus.co.uk/sexl.html

5. Find creative ways to enjoy sex and intimacy despite arthritis pain. DePuy Orthopaedics, Indianapolis, IN, USA. Internet. accessed Dec 18, 2008. Available from: http://www.allaboutarthritis.com/ AllAboutArthritis/layoutTemplates/html/en/contentdisplay/ document/condition/arthritis/generalArticle/Sex_and_arthritis.htm

6. Kaufman M. Easy for you to say: Q\&As for teens living with chronic illness or disability. Toronto: Key Porter Books; 2005.

J Rheumatol 2009;36:6; doi:10.3899/jrheum.081158 